Externalities Awareness in Anticommons Dilemmas Decreases Defective Behavior

\author{
Kristof Dhont ${ }^{1}$, Alain Van Hiel ${ }^{1}$, \& David De Cremer ${ }^{1,2}$ \\ ${ }^{1}$ Ghent University, Department of Developmental, Personality and Social Psychology \\ ${ }^{2}$ Erasmus University, Rotterdam School of Management
}

Word count: Approx. 9400; Tables and Figures included

Running head: Externalities awareness in anticommons dilemmas

Correspondence concerning this article should be sent to Kristof Dhont or Alain Van Hiel, Department of Developmental, Personality and Social Psychology, H. Dunantlaan 2, B-9000 Ghent, Belgium. E-mail addresses: Kristof.Dhont@UGent.be and Alain.VanHiel@UGent.be. 


\begin{abstract}
The present article explores the effect of the salience of collective consequences of opportunistic behavior in commons and anticommons dilemmas. Making this type of externalities salient was expected to increase the awareness of the conflict between collective and personal interests, especially in the anticommons dilemma. The results of a vignette study (Study $1, N=100$ ) and a laboratory experiment (Study 2, $N=55$ ) confirmed our hypotheses, revealing more opportunistic behavior in the anticommons than in the commons dilemma when externalities were not made salient, while no significant dilemma effect was obtained when the externalities were made salient. Moreover, the results of Study 2 demonstrated that the dilemma effect on cooperation was mediated by externalities awareness. The positive effects of increments in externalities awareness on cooperation are discussed.
\end{abstract}

KEYWORDS: anticommons, social dilemmas, commons, cooperation, decision making, awareness, externalities 
Externalities Awareness in Anticommons Dilemmas Decreases Defective Behavior

Since Hardin (1968) illustrated the risk of tragedies in common resource dilemmas, choice behavior in this type of social dilemma has elicited a growing research interest (e.g. Dawes, 1980; Dietz, Ostrom, \& Stern, 2003; Komorita \& Parks, 1995; Ostrom, 1999; Weber, Kopelman, \& Messick, 2004). The significance of this research enterprise is difficult to overestimate given the threatening real-life instances of such dilemmas, vividly exemplified by overfishing in oceans, the unconstrained use of oil reserves, and deforestation.

During the last decade, the economic literature on commons dilemmas has elicited considerable debate. In particular, a number of theorists have asserted that its mirror image - the anticommons dilemma - may also have such negative effects (e.g. Heller, 1998; Heller \& Eisenberg, 1998). Under an anticommons property regime, all owners hold the right to exclude each other from using a common resource, but none of them can use the resource without the permission of all the co-owners. Some authors (e.g. Vanneste, Van Hiel, Parisi, \& Depoorter, 2006) have reported that people ask significantly higher prices for a part of an anticommons property than the value they would take from an analogous commons property.

Given the marked differences in choice behavior in commons and anticommons dilemmas, we need to understand why these behavioral differences emerge. In our opinion, these differences might be based on people's awareness of the collective consequences of their choice behavior, in the economic literature referred to as an important type of 'externalities' (e.g. Fennell, 2004; Mundell, 1968) assumed to be a major determinant of people's choice behavior. In the present study, we therefore 
investigate the impact of increasing the awareness of the collective consequences of choice behavior, further referred to with the general term of 'externalities awareness', on behavioral decision making in both commons and anticommons dilemmas.

\section{The Commons Dilemma}

Garrett Hardin's (1968) 'tragedy of the commons' provided insights into topics as diverse as overpopulation, air pollution, and species extinction. Hardin's (1968) analysis was based on the assumption that many real-life social dilemmas are analogous to the overgrazing problem herdsmen face when their herds of sheep use the same pasturage. Here, each herdsman has the opportunity to add more sheep to his herd, leading to a greater yield (e.g. more wool). This positive outcome accrues to the individual herdsman, whereas the negative consequences (e.g. overgrazing of the commons) will be shared by all. The most rational and beneficial thing for each herdsman personally to do is to increase his herd, but this in turn will evoke a pervasive social tragedy: the pasture will be destroyed and no one will benefit in the long term. Hence, all herdsmen would be better off if they decide to cooperate by maintaining the optimal number of sheep.

In more formal terms, the theory holds that as the number of individuals who enjoy free access to a common resource grows larger relative to its capacity, the total harvest of anyone involved will approach unsustainable levels that risk its complete destruction. Hence, if a depletable resource is open to access by multiple owners who do not have the effective right to exclude each other from harvesting the common resource, incentives for overutilization emerge. In line with this theory, research on commons dilemmas has revealed that there is a real danger of a wretched ending for commons property. Indeed, it has been extensively shown that over time people harvest more from the resource than its reproduction value, thereby depleting the 
resource (for an overview, see Weber et al., 2004). According to Hardin $(1968,1998)$, one of the structural solutions to this tragedy is to remove resources from the public domain and hand them over to private ownership. In the next section, we discuss this possible solution.

\section{The Anticommons Dilemma}

Can privatization of common resources solve the problem of overutilization of these resources? Some studies have shown that when a resource is owned privately it is depleted less rapidly than when it is shared as public property among members of a group (Cass \& Edney, 1978; Martichuski \& Bell, 1991; Smith, 1981). This finding seems to offer convincing pro-arguments for the positive effect of privatizing publicly owned goods. Conversely, van Dijk and Wilke (1997) have shown that the presentation of a commons as a partitioned property does not yield these positive effects, and may even intensify the harvesting problems. Moreover, recent writings on the anticommons dilemma showed that privatization may lead to detrimental side effects (Heller, 1998). For example, Heller and Eisenberg (1998) have described the consequences of anticommons property rules for the development of biomedical research.

Specifically, they discussed the example of a research team that wants to develop a new important medicine for the treatment of the human immunodeficiency virus (HIV). The team needs to have patents from different firms to develop the medication. Because different firms own the patents, every single patent holder is eventually in a position to exclude a downstream user from developing the new medicine. Moreover, since none of the owners knows initially which patent will be the key for the new medicine, every patent holder tends to demand more money for his/her invention than its actual value. In the end, because the collective demanding 
price is more than the cumulative market value of the end product, the research team has to forsake further development of the HIV medicine. Another net result emerging here is that all patent holders lose money because their patents are unused, even though the use of these patents is in great demand. Further examples of anticommons tragedies are the market for human tissue (Mahoney, 2000), underuse of Internet resources (Hunter, 2003), and copyright protection (Depoorter \& Parisi, 2002).

In more formal terms, the theory holds that when multiple owners all possess the right to exclude each other from benefiting from a scarce resource, the resource might tend to be underused. The tragedy of the anticommons occurs when co-owners exert their exclusion rights by withholding resources excessively from other users. As a result, the full value of the resource is not realized.

Property Structure and Rights in Commons and Anticommons Dilemmas Recent literature in economics and property law (Buchanan \& Yoon, 2000; Fennell, 2004; Parisi, Schulz, \& Depoorter, 2005) highlights the symmetrical property structure of commons and anticommons. According to the traditional concept of property, owners enjoy a complementary bundle of rights over their property, including the right to use the property and the right to exclude others from it. As can be seen in Figure 1 (adapted from Vanneste et al., 2006), commons and anticommons conditions can be conceived as symmetric deviations from the standard bundle of rights, whereby the rights of use and exclusion are kept in balance. Thus, in commons situations, the right to use the property stretches beyond the effective right (or power) to exclude others. Conversely, in an anticommons property regime, the co-owners' right of use is crowded out by a dominant right of exclusion held by other co-owners. 
On a theoretical plane, using formal models, Buchanan and Yoon (2000) demonstrated that commons and anticommons problems result in equal welfare losses (see also Fennell, 2004; Parisi et al., 2005). However, unlike these formal algebraic models, Vanneste et al. (2006) showed in two empirical studies that underuse in anticommons properties may reflect a greater problem than overuse in equivalent commons properties. Specifically, in their study, participants in the commons condition were asked to take whatever they wished from a common resource (see also van Dijk \& Wilke, 2000), while in the anticommons condition, participants established a value that they wished to receive for their part of the common property. The findings of Vanneste et al. (2006) showed that the anticommons condition yielded significantly higher asking prices than the amount of money taken in the commons condition.

If the commons and anticommons dilemmas constitute symmetric departures from the standard situation of full ownership in terms of structural properties, why then do people ask higher prices in an anticommons dilemma than the monetary amount they would take in an equivalent commons dilemma?

\section{Externalities Awareness}

A variable at the center of the present article is the awareness of the collective consequences of defective behavior. These costs are not directly accruing to the actor who made the decision, but are rather received or paid by the collective or imposed on the resource. We refer to these external costs by the general term 'externalities' (Mundell, 1968). According to this perspective, when actors fail to internalize the consequences for everyone involved (the whole collective of co-owners), cooperation will not occur (e.g., Fennell, 2004; Parisi, et al., 2005; Schulz, Parisi, \& Depoorter, 2002). Conversely, if the owners internalize the externalities, rational decision makers 
will choose to cooperate, thereby increasing the likelihood that all parties benefit and that the full value of the common property can be realized.

Previous studies seem to suggest that externalities awareness may yield the assumed positive effect. In particular, some studies have revealed that informing owners about the long-term negative effects of defective actions and the benefits of cooperation leads these owners to exhibit higher levels of actual cooperation and resource management efficiency (e.g., Foddy \& Veronese, 1996; Rapoport, 1988; Schroeder, Jensen, Reed, Sullivan, \& Schwab, 1983; Stern, 1976; Thompson \& Stoutemeyer, 1991). Moreover, unveiling the externalities of a dilemma does not only affect the perception of this dilemma, but also may have implications at the moral level. In particular, Schwartz (1970) argued that people only behave cooperatively when the consequences of their actions for others are salient to them (see also Schwartz, 1977; Schwarz \& Howard, 1982; van Dijk \& Wilke, 1997). Hence, only when the negative consequences of non-cooperative behavior for others are clear, people are in a position to feel social responsible for their decisions, and thus are morally convinced that cooperation is the right thing to pursue.

Cooperation is thus facilitated by turning people's attention to the collective consequences of their behavior. We argue that externalities awareness will matter in explaining the behavioral differences between the commons and anticommons dilemma because the implications of defective behavior in the commons dilemma are less ambiguous than those of the anticommons dilemma (see, Schulz, et al., 2002; Vanneste et al., 2006). In other words, the externalities in the commons dilemma are more salient compared to the externalities in the anticommons dilemma. According to Vanneste et al. (2006): “...most people readily comprehend that unrestrained use of common resources leads to total depletion of resources in the long run, and that those 
who take more than their share out of the commons preclude others from partaking of its benefits" (p. 117). Indeed, under commons property rules, the collective property and its productive capacity can be clearly perceived at the very moment people decide whether they will cooperate or defect. As such, the consequences of the chosen actions are apparent as well. Thus, co-owners of a commons property can be expected to have some awareness of the fact that taking too much is bad for the collective interests. In economic terms, then, it is suggested that co-owners of a commons property are relatively apt to internalize the costs of non-cooperation in a commons dilemma.

Conversely, the social dilemma character of an anticommons property may be less salient, increasing the difficulty of detecting collective consequences. Indeed, people have to make decisions about the value of collective property that has not yet been created (e.g., new medication based on multiple privately owned patents) or is not currently productive (e.g., fragmented land that is currently unused). As such, because the collective benefits of property still have to be realized, and the negative consequences resulting from doing nothing are not instantly present (e.g., not using the patents), externalities awareness may be difficult to achieve. According to Kopelman (2009), this basic ambiguity of anticommons dilemmas makes people more likely to be influenced by cognitive biases, leading them only to pay heed to their personal benefits. In particular, people are likely to attribute higher values to their individual part of the property and may systematically undervalue the assets of the others. In economic terms, Schulz et al. (2002) argued that anticommons dilemmas make people prone to 'forget' “... that the exercise of a right of exclusion ... reduces or eliminates the value of similar rights held by other individuals" (p. 595). Moreover, people may be less attentive to the fact that " ... the underuse of productive inputs 
today bears [negative] consequences into the future..." (p. 595). In sum, co-owners of an anticommons property are relatively blind to the costs of non-cooperation in an anticommons dilemma, thereby failing to internalize these costs.

The Present Research

To summarize, we argue that the externalities are less salient in anticommons than in commons dilemmas. As such, the differential externalities salience makes people more or less aware of the externalities, leading them, in turn, to behave more versus less cooperatively, respectively. Given that making the externalities salient makes people more aware of them, people are expected to act more cooperatively when externalities salience is high, especially in the anticommons dilemma, thereby reducing the behavioral differences between commons and anticommons dilemmas.

Based on our review of the literature, three main hypotheses have been formulated:

Hypothesis 1. When externalities are salient, people exhibit relatively higher levels of cooperative choice behavior than when externalities are not salient. Hypothesis 1 thus states a main effect of externalities salience.

Hypothesis 2. When externalities are not salient, anticommons dilemmas elicit higher levels of non-cooperative choice behavior than commons dilemmas. In contrast, under conditions that make the externalities salient, the differences between commons and anticommons conditions are curbed. Because making the externalities salient has the most pronounced effects on choice behavior in anticommons dilemmas, Hypothesis 2 states an interaction effect between dilemma type and externalities salience.

Hypothesis 3. The higher levels of non-cooperation in anticommons compared to commons dilemmas under low externalities salience can be explained by the lower 
level of externalities awareness. Hypothesis 3 thus states that when externalities are not made salient, awareness of the externalities mediates the main effect of dilemma type on cooperation.

Two studies were conducted to test the present hypotheses. In the externalities salient conditions, we made participants aware of the externalities by stressing the negative consequences of non-cooperative choice behavior for the other owners as well as for the common property. In the externalities not salient conditions, no such information was given. The strategy of manipulating information availability has the advantage that the dilemma structure remains completely analogous across the externalities salience conditions.

In Study 1, we presented participants a hypothetical scenario in which a commons or anticommons dilemma situation was presented and the externalities were (not) made salient. In Study 2, we conducted an experimental lab study in which participants played a commons or anticommons dilemma game. Initially, participants made their choices without receiving information about the externalities (externalities not salient) and were probed into their externalities awareness. Subsequently, the externalities were made salient and they played a second round.

\section{STUDY 1: VIGNETTE STUDY}

\section{Method}

\section{Participants and Design}

The participants were 100 volunteering undergraduate psychology students at Ghent University $\left(M_{\text {age }}=19.39, S D_{\text {age }}=1.60 ; 55 \%\right.$ female $)$. The study had a $2 \times 2$ factorial design with dilemma type (commons versus anticommons) and externalities salience (salient versus not salient) as between-subject variables. 
The study was part of a classroom exercise and participants were randomly assigned to one of the four conditions, which were presented in an experimental vignette. The commons and anticommons dilemma tasks were based on the oil company scenario used by Van Hiel, Vanneste, and De Cremer (2008) and Vanneste et al. (2006, Study 2) and adapted to the four conditions. Participants read a scenario and subsequently made a bid on a pay-off scheme. Afterwards, they completed the manipulation check.

Across all conditions, the basic dilemma structure and situation were completely analogous. Participants were presented with the following situation: "You are a co-owner of an oil well which is exhaustible. Besides your own company, there are four other co-owning companies. Your main objective is to gain as much money as possible. Of course, the other companies have the same objective."

Participants further read a text dependent upon the experimental condition. In the commons condition, it was asserted "Each year you have to make a bid regarding how much oil you want to take from the well." The text ended with the question how much oil (expressed in euro) the participant is taking, not knowing how many the other owners will take. Participants made a bid and marked their choice on a pay-off scheme (see Table 1) ranging from $€ 0$ to $€ 60000$.

In the anticommons condition, it was asserted: “At this moment co-owner B wants to drill a part of the oil well, but the four other companies (including yours) have to grant him/her permission for this. You should know that the amount of oil that will be gained by B cannot be drilled by you at a later stage." The text ended with the question how much money the participant wants to ask for his/her part of the source, not knowing how much the other owners will ask. Participants made a bid and marked their choice on a pay-off scheme (see Table 1) ranging from $€ 0$ to $€ 60000$. 
Besides the dilemma type, we also manipulated a second variable: the salience of the externalities. In the externalities not salient conditions, no extra information was given about the possible danger of over or underuse in the commons and anticommons conditions respectively and only the first two columns of the pay-off scheme were presented.

In the externalities salient condition, additional information about the consequences of non-cooperative and cooperative choice behavior was explained before participants had to indicate their bid on the pay-off scheme. The danger of overuse in the commons condition and underuse in the anticommons condition was clearly emphasized.

Thus, in the commons condition, with the externalities salient it was asserted: "if you take the maximum amount, there is a real danger that the other companies can drill less oil. Therefore, it may be in the companies' collective interests that everyone drills less oil. Obviously, it may be to each company's individual advantage to take as much as possible." Furthermore, it was stressed that if the owner drills oil, he/she makes use of the source as well as the materials to drill the oil. Hence, the source will be liable to wear and decline and as a result the value of the source will decrease. The text ended with "The more oil you take, the more likely that the source value will decrease." Besides this extra information, the information in the pay-off scheme was also extended to all columns of Table 1.

\section{Insert Table 1 about here}

In the anticommons condition, with the externalities salient it was asserted: "If you and the three other companies ask for the maximum amount, then there is a real danger that B will not buy a part of the well leaving the other companies (A, C, D, and E) 'out in the cold'. Thus, it may be to the companies' collective advantage to ask 
less money. Obviously, it may be to each company's individual advantage to ask as much as possible." Furthermore, it was stressed that if owner B can drill oil, he/she will maintain the source and the drill materials so that the source value will be preserved. The text ended with "The higher the price you ask, the less likely owner B is to buy and thus maintain the source, the more likely that the source value will decrease." Analogous with the commons condition, the information in the pay-off scheme was extended to all columns of Table 1.

Participants finally completed an item that checked whether participants in the externalities salient condition appropriately read and understood the additional information, compared to participants in the externalities not salient condition. The item asked whether participants "were aware that if all owners take/ask a substantial amount of money, it would be likely that the value of the source would decrease. Thus, taking/asking a lot of money is bad for the collective interests". This item had to be rated on a 6-point scale ranging from totally unaware (1) to totally aware (6).

\section{Results}

\section{Manipulation Check}

First, we subjected the item score on the manipulation check to a 2 (dilemma type: commons versus anticommons) x 2 (externalities not salient versus externalities salient) univariate ANOVA. The results only showed a main effect of externalities salience, $F(1,96)=88.15, p<.001, \eta^{2}=.48$, revealing that our manipulation was successful. Participants in the externalities salient condition $(M=5.02)$ reported being more aware of the externalities than the participants in the externalities not salient condition $(M=2.72)$.

\section{Choice Behavior}


We subjected the choice behavior data to a 2 (dilemma type: commons versus anticommons) x 2 (externalities not salient versus externalities salient) univariate ANOVA. Figure 2 presents the mean amounts of money and standard deviations for each condition.

In line with Hypothesis 1, we obtained a significant main effect of externalities salience, $F(1,96)=66.13, p<.001, \eta^{2}=.41$. Furthermore, replicating Vanneste et al. (2006), a main effect of dilemma type was obtained as well, $F(1,96)=21.36, p<$ $.001, \eta^{2}=.18$. Importantly, in line with Hypothesis 2, a significant interaction emerged, $F(1,96)=4.06, p<.05, \eta^{2}=.04$ (see Figure 2).

\section{Insert Figure 2 about here}

To interpret this interaction effect, we conducted simple effects analyses. As predicted by Hypothesis 2, the dilemma effect was significant in the externalities not salient condition, $F(1,96)=20.78, p<.001, \eta^{2}=.18$, whereas this effect was much weaker in the externalities salient condition, and did not attain the conventional significance level $(p<.05), F(1,96)=3.60, p=.06, \eta^{2}=.04$.

\section{Discussion}

In this first study, we manipulated externalities salience as well as dilemma type. In line with Hypothesis 1, it was shown that when the externalities were made salient, people harvested significantly less than when the externalities were not made salient. This finding demonstrates the impact of manipulating the salience of the externalities. Furthermore, in line with Hypothesis 2, a significant interaction effect between dilemma type and externalities salience emerged, revealing a rather large dilemma effect in the externalities not salient condition, whereas this effect was only marginally present in the externalities salient condition. 
However, although the results of Study 1 supported Hypotheses 1 and 2, the study might be faulted for its scenario methodology examining hypothetical decisions rather than actual behavior. Hence, in Study 2 we aimed to extend the findings of Study 1 by investigating actual decision behavior in an experimental lab study.

\section{STUDY 2: LAB EXPERIMENT}

In this lab study, participants played an experimental game in which they made their choices once without (externalities not salient) and once with receiving information about the externalities (externalities salient). In addition, Study 2 also directly addressed the question whether externalities awareness accounts for the differences in choice behavior between commons and anticommons dilemmas. This mediation effect was studied in the first phase of the experiment, when the externalities had not been made salient yet. More specifically, as outlined in Hypothesis 3, under low externalities salience, awareness of the externalities was expected to mediate the effect of dilemma type on choice behavior. Hence, we also measured participant's externalities awareness in order to test its mediating role.

\section{Method}

\section{Participants and Design}

A total of 55 undergraduate students $\left(M_{\text {age }}=21.30, S D_{\text {age }}=2.27 ; 77 \%\right.$ female) were paid for voluntary participation in this experiment. The present study had a $2 \times 2$ design with externalities salience (externalities salient versus not salient) manipulated as a within-subject variable and dilemma type (commons versus anticommons) as a between-subject variable. Participants were randomly assigned to the dilemma condition.

\section{Procedure}


Five participants were scheduled for each session. Upon arrival at the laboratory, participants were seated in separate cubicles in front of a computer and were led to believe that their computers were interconnected. All further instructions, stimulus materials, and questionnaires were presented on computer screen using the Tscope $\mathrm{C} / \mathrm{C}++$ programming library (Stevens, Lammertyn, Verbruggen, \& Vandierendock, 2006).

Participants were instructed to play a collective game. Dependent on the dilemma condition they read the initial task instructions pertaining to a commons or an anticommons dilemma without information about the externalities. Subsequently, they played a first round in which they made a bid and completed a measure that probed into their awareness of the externalities. Next, they were given information about the externalities, after which they played a second round, completing the same measures as in the first round. Participants were not forewarned that the game would end after these two rounds.

Dilemma Game. Across all conditions, the basic dilemma structure and situation were completely analogous, and the dilemma was based on the oil company scenario used in Study 1. It was told to the participants that they were co-owner of a communal oil well containing an exhaustible amount of oil barrels (12000 barrels, worth $€ 480000)$

In the commons condition, participants had to choose how much oil they want to take from the well. Each round, participants could earn money by taking oil out of the oil well for an amount ranging between $€ 0$ and $€ 140000$, being uninformed about the other player's intentions. No further information about the other players or about specific resource characteristics was given. 
In the anticommons condition, it was asserted that if one of the participants wants to use the oil well, he or she has to financially compensate the other four players. Hence, each round, participants in the anticommons condition indicated the amount of money ranging between $€ 0$ and $€ 140000$ they wanted to receive for their part of the property, being uninformed about the other player's intentions. As in the commons condition, no further information about the other players or about specific resource characteristics was given.

After reading the information, participants received some comprehension questions probing their understanding of the game. If one or more incorrect answers were given, the information and the questions were presented again. Next, participants were asked to choose the amount of money they wanted to receive, followed by the message to wait until all participants have made their bids. After a short time lag participants were asked to complete the measure of awareness of the externalities.

Next, before playing the second round participants were informed that the value of the oil well was decreased as a result of the first round. Participants in the commons condition were further explained that the total amount asked by all owners in Round 1 is taken away from the oil well, decreasing its value. In the anticommons dilemma it was explained that no one bought oil because the total price demanded by all participants was higher than the amount participants were willing to pay. Therefore, the oil-well was not appropriately maintained, decreasing its value. In order to keep the feedback consistent across participants and across dilemma type, no specific information was given about the choices of the other co-owners and about the exact decrease in value of the oil-well. After receiving this general feedback, information about the externalities was presented. 
In the commons condition, it was asserted that: "if you take the maximum amount of money, there is a real danger that the other participants can drill less oil. As a result, no-one will be able to fully profit of the well. Thus, in terms of collective interests, it is better that everyone takes less money. Obviously, it is in each participant's individual advantage to take as much as possible." Furthermore, it was explained that if each participant restricts him/herself to take oil for a maximal amount of money of $€ 15000$, the oil well regenerates itself and keeps its value for a $100 \%$. It was also stressed that the more the owners drill oil, the more they make use of the source as well as the materials to drill the oil. Hence, the source would be liable to wear and decline and as a result the value of the source would decrease. It was finally stated: "The more oil you take, the more likely that the source value will decrease."

In the anticommons condition, it was asserted that: "If you and the other participants ask the maximum amount of money there is a real danger that all buyers will decline trying to acquire the well. As a result, no-one will be able to fully profit of the well. Thus, in terms of collective interests, it is better that everyone asks less money. Obviously, it is in each participant's individual advantage to ask as much as possible." Furthermore, it was explained that if each participant restricts him/herself to ask prices for a maximal amount of $€ 15000$, there would be $100 \%$ certainty that the sale would go on. It was also stressed that if nobody would use the oil well, the source and the drill materials would not be maintained. Hence, the source would be liable to wear and decline and as a result the value of the source would decrease. It was finally stated: "The higher the price you ask, the more likely that the source value will decrease." 
In both the commons and anticommons condition the text ended with two examples explaining what would happen when each participant asks more than $€ 15000$, as well as the consequences of each participant asking $€ 15000$ or less. After correctly answering a comprehension question, participants indicated their bids and completed the measure of awareness of externalities again.

Awareness of Externalities The measure of awareness of the externalities consisted of four items which had to be rated on a 9-point scale ranging from totally unaware (1) to totally aware (9). Sample items are: "Were you aware of the fact that if all participants would ask a small amount of money, it would be more likely that everyone benefit?" and "When choosing an amount of money, did you consider that if all participants would ask a substantial amount of money, it is very likely that de value of the source decreases, which is bad for collective interests?" This measure proved to be internally consistent ( $\alpha=.91$ and $\alpha=.81$, for the first and second round, respectively).

\section{Results}

\section{Choice Behavior Data}

Data of three participants were excluded because of computer problems or because of failure to follow the instructions appropriately. In order to test Hypotheses 1 and 2, we subjected the choice behavior data (see, Figure 3a) to a repeated measures ANOVA with externalities salience as a within-subject variable and dilemma type as a between-subject variable.

Consistent with Hypothesis 1, a significant main effect was obtained for externalities salience, $F(1,50)=60.43, p<.001, \eta^{2}=.56$. The effect of dilemma type was also significant, $F(1,50)=5.48, p<.05, \eta^{2}=.10$. In corroboration with Hypothesis 2, we obtained a significant dilemma type $\mathrm{x}$ externalities salience 
interaction, $F(1,50)=5.23, p<.05, \eta^{2}=.10$, showing that participants in the anticommons condition asked significantly higher amounts of money than participants in the commons condition when the externalities were not salient, $F(1,50)=5.48, p<$ $.05, \eta^{2}=.10$, while the dilemma effect was curbed (and even non-significant) when the externalities were made salient, $F(1,50)=.69, p=.41, \eta^{2}=.01$.

\section{Insert Figure 3 about here}

\section{Externalities Awareness}

As can be seen in Figure 3b, similar to the results of the choice behavior data, we obtained significant main effects for externalities salience and dilemma type, $F(1$, $50)=76.64, p<.001, \eta^{2}=.61$, and $F(1,50)=8.87, p<.005, \eta^{2}=.15$, respectively, as well as a significant dilemma type $\mathrm{x}$ externalities salience interaction, $F(1,50)=$ $10.49, p<.005, \eta^{2}=.17$, on externalities awareness. In line with our expectations, participants in the anticommons condition were less aware of the externalities compared to participants in the commons condition when the externalities were not salient, $F(1,50)=12.24, p<.001, \eta^{2}=.20$, while no such significant differences were found when the externalities were made salient, $F(1,50)=.18, p=.68, \eta^{2}=.004$.

\section{Mediation Analyses}

Finally, we tested Hypothesis 3 stating that when the externalities are not made salient, externalities awareness mediates the dilemma effect on choice behavior. Hence, in the following analyses, only the choice behavior data of the first round (before the externalities were made salient) were included as a dependent variable. Following Baron and Kenny (1986), we conducted a series of regression analyses to test the mediation effect of externalities awareness. Four conditions need to be met. First, the independent variable has to significantly influence the dependent variable. The significant effect of dilemma type on choice behavior data, $\beta=.31, p<.05$, 
fulfills this first requirement. Second, the effect of the independent variable on the mediating variable has to be significant, which was confirmed by the present data as dilemma type was strongly related to externalities awareness, $\beta=-.44, p<.05$. Third, when regressing the dependent variable on both the independent variable and the mediator, a significant effect of the mediator has to be shown. Fourth, the effect of the independent variable has to dissipate when accounting for the mediator. In line with the two latter requirements, a regression analysis simultaneously including dilemma type and externalities awareness as predictors of choice behavior revealed a significant effect of externalities awareness, $\beta=-.35, p<.05$, whereas the effect of dilemma type was reduced to non-significance, $\beta=.16, p>.26$. Additionally, a Sobel test confirmed that externalities awareness significantly mediated the effect of dilemma type on choice behavior, $z=2.00, p<.05$.

\section{Discussion}

The results of Study 2 replicated the findings of Study 1, corroborating Hypotheses 1 and 2. In particular, we demonstrated that participants posted lower bids in the externalities salient condition than in the externalities not salient condition (Hypothesis 1), and that the dilemma effect was curbed when the externalities were made salient (Hypothesis 2). Furthermore, in line with Hypothesis 3, we also showed that the higher levels of non-cooperation in anticommons compared to commons dilemmas in the externalities not-salient condition can be ascribed to lower levels of externalities awareness. The reader may have noticed that, similar to Study 1, also Study 2 used an oil well as the common good. A question arising here is whether similar results would have been obtained with other types of common properties. However, given that Van Hiel et al. (2008) reported related findings using different 
hypothetical situations, we are confident that the present findings would also emerge with other common goods.

\section{GENERAL DISCUSSION}

The present two studies focused on the effect of salience of externalities on cooperation in commons and anticommons dilemmas. Both studies yielded corroborative evidence for our hypotheses. Importantly, the evidence for our hypotheses was obtained using different methods (i.e. vignette study versus laboratory experiment) and different research designs (i.e. presentation of the externalities conditions in a between-subjects versus a within-subjects design). The employment of these different methodologies yielded consistent findings, which contribute to the validity of our findings.

In line with Hypothesis 1, the present studies revealed that participants asked for significantly less money when the externalities were made salient than when the externalities remained ambiguous. The present positive effects of externalities salience align well with previous research findings on environmental uncertainty in resource dilemmas. More specifically, experimental studies have shown that compared to conditions in which the resource characteristics are clear (paralleling the externalities salient condition), unawareness of the specific resource characteristics like resource size and capacity to regenerate (paralleling the externalities not salient condition) often leads to an overestimation of these characteristics and to an overuse of the resource (Budescu, Rapoport, \& Suleiman, 1990; de Kwaadsteniet, van Dijk, Wit, De Cremer, \& de Rooij, 2007; Gustafsson, Biel, \& Gärling, 1999, 2000; Hine \& Gifford, 1996; van Dijk, Wit, Wilke, \& Budescu, 2004). In other words, these previous studies as well as the present studies clearly showed that when people have 
received full information, possibly leading to higher levels of externalities awareness, they refrain from excessively harvesting the common resource.

The main objective of the present study, however, was to show that anticommons dilemmas elicit more defective behavior than commons dilemmas (Vanneste et al., 2006), exactly because of low externalities awareness. In accordance with Hypothesis 2, we demonstrated that the difference in choice behavior elicited by these two dilemma types can be reduced to non-significance by increasing the externalities salience. Moreover, in accordance with Hypothesis 3, it was revealed that the underlying psychological mechanism accounting for the higher levels of selfish behavior in anticommons relative to commons dilemmas, resides in the lack of externalities awareness.

In the following sections, we further go into depth into our findings pertaining to Hypotheses 2 and 3. In particular, we first elaborate upon the possible causes and implications of (the lack of) externalities awareness in the anticommons dilemma. Then, we discuss whether loss aversion may offer an alternative explanation for the present findings and we also elaborate on the co-occurrence of rational and moral considerations to cooperate. Finally, some limitations of the present studies and suggestions for future research are highlighted.

The Hidden Costs of the Anticommons Dilemma

Selfish behavior under a commons regime represents a major threat to society and humanity worldwide. At first glance, an efficient way of dealing with this problem of overuse is dividing the common good into private segments (e.g., Hardin, 1968). Martichuski and Bell (1991), for instance, showed that when the common resource was divided into private segments so that individuals managed their own access to a private segment, they were more effective in maintaining the resource. 
However, the theoretical work of Heller (1998; Heller \& Eisenberg, 1998) highlighted the detrimental problems of underuse which may arise when privatization is structured as an anticommons property regime. In line with the work of Heller and colleagues, the present data as well as previous studies (Van Hiel et al., 2008; Vanneste et al., 2006) demonstrated that anticommons property regimes may elicit even more selfish choice behavior than an equivalent commons dilemma.

The present results reveal that people who are involved in the commons dilemma seem to some extent aware of the negative consequences of non-cooperative behavior, while in the anticommons dilemma people only seem to be aware of the individual benefits of defecting. This finding concurs with Van Hiel et al. (2008) who reported that cooperative targets were attributed higher levels of ignorance (indicative of the attributer's poor externalities awareness) than non-cooperative targets in an anticommons dilemma, whereas an opposite pattern of results was obtained for the commons dilemma. According to Van Hiel et al. (2008), these results are indicative of the presence of a strong self-centered rationality in the anticommons dilemma. The present results combined with Van Hiel et al. (2008), then, suggest that unveiling externalities of the anticommons dilemma (i.e., lowering ignorance) transforms the underlying rationality principle (see, Liebrand, Jansen, Rijken, \& Suhre, 1986) from the individual level to the group level, making cooperation more likely to occur.

A possible reason why the externalities are more salient in the commons than in the anticommons dilemma resides in the structural features of these dilemmas. The productive capacity of a property under commons property rules is already present at the moment when people have to decide whether they will cooperate or defect. In other words, the property is initially perceived at its full potential, and it is reasonably clear to the owners that taking much of its value may be harmful. In contrast, under 
anticommons property rules, people deal with a non-productive property or property that has yet to be created at the moment they are required to make decisions about the value of that property (Kopelman, 2009). Hence, the positive effects of cooperation tend to be 'hidden' in the future, and people only become aware of losses in the long run.

In sum, when an anticommons dilemma is at stake, it is thus important to unveil its 'dilemma character'. For example, the considerable impact of the work of Heller (1998; Heller \& Eisenberg, 1998) on law and economic literature can probably be attributed best to its surprising and innovative insights in the domain of patenting, which had previously gone unnoticed. Indeed, Heller and Eisenberg's (1998) theoretical development of the anticommons dilemma and its application to the patenting system have clearly shown the hitherto hidden costs of patenting and caused increased attention and discussion about the usefulness of patents (e.g. Buckley, 2007; Epstein \& Kuhlik, 2004; Scherer, 2002). The controversy on the patenting system presents us with a vivid example of the unexpected insights generated by the deconstruction of situations in terms of an anticommons dilemma, and the work of Heller and colleagues might be rightfully considered to raise externalities awareness about such situations.

\section{Ownership and Moral Suasion in Anticommons Dilemmas}

An alternative explanation for the higher prices under anticommons property rules should be mentioned. In particular, the claim of higher prices to give up (or, 'to lose') a part of the property under the anticommons regime compared to the amounts co-owners 'gain' under a commons regime might be interpreted as an endowment effect (Thaler, 1980, van Dijk \& van Knippenberg, 1996). Within this perspective, the owners in an anticommons regime would be asking higher prices as a strategy to 
compensate for giving up an object, reflecting loss aversion. However, although this interpretation in terms of endowment is tempting, there are several fundamental differences between an anticommons dilemma and a classic dyadic bargaining situation. Unlike bargaining situations, a typical ingredient of the anticommons regime is the fragmentation of property resulting in a different and more complex interdependence structure of co-ownership. Indeed, in an anticommons dilemma, both the potential buyer and sellers might be co-owners of the property. Hence, given that it is already difficult to define choices as losses or gains in most social dilemma types, (Schwartz-Sea \& Simmons, 1995), this might even prove more difficult in the anticommons dilemma. Furthermore, in many anticommons dilemmas, like for instance granting permission to use a patent in exchange for money, one does not lose ownership and the right to exclude others from the property, rendering an explanation in terms of endowment cumbersome.

A second important issue arising here concerns the question by which considerations people become motivated to cooperate. Our manipulation of externalities awareness is focused on rational considerations, but it cannot be denied that this manipulation may have spill-over effects in the moral domain, in the sense that it may indicate 'the right thing to do'. It should be stressed, however, that unlike studies on moral suasion (Martichuski \& Bell, 1991; see also Orbell \& Dawes, 1981), the present manipulation of externalities awareness did not explicitly formulate moral standards for conduct. Based on the present data, however, we cannot draw a sharp line between 'cool cognition' and 'moral obligations' because rational and moral considerations often co-occur. The reason for this match of rationality and morality resides in the basic nature of a social dilemma, that is, in the mere fact that long term 
cooperation leads to a better conservation of the common good as well as to increased benefits for anyone involved.

\section{Limitations and Suggestions for Future Research}

Before closing, we want to highlight several important issues that may lead to interesting future studies. First, the present studies focused on the effects of the salience of one general type of externalities, namely the collective consequences of opportunistic behavior. Further research is required to investigate the impact of the salience of other externalities types, such as negative external costs for third parties uninvolved in the decision making, as well as the impact of other well-known determinants of cooperation in social dilemmas, such as social uncertainty or social value orientation (see Weber et al., 2004). Indeed, once people are aware of the collective consequences of their behavior and correctly identify the dilemma character of the situation, these other determinants of cooperation are still likely to have effects.

Another interesting issue is whether the underuse of a common resource under anticommons property regime may turn out to have beneficial effects for the group of co-owners. For instance, claiming high prices for an almost depleted resource may reduce the demand, thereby allowing the resource enough time to regenerate itself.

Finally, it is plausible that the use of one- and two-shot dilemmas may have not given a full picture of the impact of externalities salience. Future research may apply a sequential game procedure to investigate the longitudinal course of participant's choice behavior. Indeed, at this moment it remains unclear whether the decrease in opportunistic behavior caused by salient externalities will stagnate, continue, or conversely, disappear and turn back into selfish behavior, and how this decrease may be facilitated or inhibited by associating real monetary awards to participants' decisions. 


\section{Conclusion}

In conclusion, the present research contribute to our understanding of behavioral decision making in commons and anticommons dilemmas by addressing the question why people behave more opportunistically in an anticommons dilemma than in an equivalent commons dilemma. The present studies showed that making salient the externalities successfully evoked cooperative behavior, particularly in the anticommons dilemma. Hence, revealing the externalities is likely to be a promising way to deal with the problem of underuse in anticommons dilemmas, without making complex structural changes concerning the underlying property rights and rules. 


\section{REFERENCES}

Baron, R. M., \& Kenny, D. A. (1986). The moderator-mediator variable distinction in social psychological research: Conceptual, strategic and statistical considerations. Journal of Personality and Social Psychology, 51, 1173-1182.

Buchanan, J. M., \& Yoon, Y. J., (2000). Symmetric tragedies: Commons and anticommons. Journal of Law and Economics, 43, 1-13.

Buckley, T. (2007). The myth of the anticommons. Biotechnology Industry Organisation, Washington, DC, 29 May 2007, 14 pp. http://www.bio.org/ip/domestic/TheMythoftheAnticommons.pdf

Budescu, D. V., Rapoport, A., \& Suleiman, R. (1990). Resource dilemmas with environmental uncertainty and asymmetric players. European Journal of Social Psychology, 20, 475-487.

Cass R. C., \& Edney J. J. (1978). Commons dilemma - simulation testing the effects of resource visibility and territorial division. Human Ecology, 6, 371-386.

Dawes, R. M. (1980). Social dilemmas. Annual Review Psychology, 31, 169-193.

de Kwaadsteniet, E. W., van Dijk, E., Wit, A., De Cremer, D., \& de Rooij, M. (2007). Justifying decisions in social dilemmas: Justification pressures and tacit coordination under environmental uncertainty. Personality and Social Psychology Bulletin, 33, 1648-1660.

Depoorter, B., \& Parisi, F. (2002). Fair use and copyright protection: A price theory explanation. International Review of Law and Economics 21, 453-473.

Dietz, T., Ostrom, E., \& Stern, P. C. (2003). The struggle to govern the commons. Science, 302, 1907-1912.

Epstein, R. A., \& Kuhlik, B. N. (2004). Is there a biomedical anticommons? Regulation Magazine, 27, 54-58. 
Fennell, L. A. (2004). Common interest tragedies. Northwestern University Law Review, 98, 907-990.

Foddy, M., \& Veronese, D. (1996). Does knowing the jointly rational solution make you want to pursue it? Motivational orientation, information, and behavior in two social dilemmas . In W. B. G. Liebrand \& D. M. Messick (Eds.), Frontiers in social dilemma research. (pp 135-155). Berlin: Springer-Verlag.

Gustafsson, M., Biel, A., \& Gärling, T. (1999). Overharvesting of resources of unknown size. Acta Psychologica, 103, 47-64.

Gustafsson, M., Biel, A., \& Gärling, T. (2000). Egoism bias in social dilemmas with resource uncertainty. Group Processes and Intergroup Relations, 4, 351-365.

Hardin, G. (1968). Tragedy of the commons. Science, 162, 1243-1248.

Hardin, G. (1998). Extensions of 'The tragedy of the commons'. Science, 280, 682.

Heller, M. A. (1998). The tragedy of the anticommons: Property in the transition from Marx to markets, Harvard Law Review, 111, 621-688.

Heller, M. A., \& Eisenberg, R. S. (1998). Can patents deter innovation? The anticommons in Biomedical Research. Science, 280, 698-701.

Hine, D. V., \& Gifford, R. (1996). Individual restraint and group efficiency in commons dilemmas: The effects of uncertainty and risk-seeking. Journal of Applied Social Psychology, 26, 993-1009.

Hunter, D. (2003). Cyberspace as place, and the tragedy of the digital anticommons. California Law Review, 91, 439-19.

Komorita, S. S., \& Parks, C. D. (1995). Interpersonal relations: Mixed motive interaction. Annual Review of Psychology, 46, 183-207. 
Kopelman, S. (2009). The anticommons dilemma: Theoretical and empirical implications for cooperation in social dilemmas. Working paper. Ross School of Business, University of Michigan, Ann Arbor.

Liebrand, W. B. G., Jansen, R. W. T. L., Rijken, V. M., \& Suhre, C. J. M. (1986). Might over Morality: Social Values and the perception of other players in experimental games. Journal of Experimental Social Psychology, 22, 203-215.

Mahoney, J. D. (2000). The market for human tissue. Virginia Law Review, 38, 103223.

Martichuski, D. K., \& Bell, P. A. (1991) Reward, punishment, privatization, and moral suasion in a commons dilemma. Journal of Applied Social Psychology, 21, 1356-1369.

Mundell, R. A., (1968). Man and Economics: The Science of Choice. New York: McGraw-Hill.

Orbell J., \& Dawes, R. (1981). Social dilemmas. In G. M. Stephenson \& J. M. Davis (Eds.), Progress in Applied Social Psychology, (pp. 37-65)., New York: Wiley.

Ostrom, E. (1999). Coping with tragedies of the commons. Annual Review of Political Science, 2, 493-535.

Rapoport, A. (1988). Experiments with N-person social traps II. Tragedy of the commons. Journal of Conflict Resolution, 32, 473-488.

Parisi, F., Schulz, N., \& Depoorter, B. (2005). Duality in property: Commons and anticommons. International Review of Law and Economics, 25, 578-591.

Scherer, F. M. (2002). The Economics of human gene patents. Academic Medicine, $77,1348-1367$. 
Schroeder, D. A., Jensen, T. D., Reed, A. J., Sullivan, D. K., \& Schwab, M. (1983). The actions of others as determinants of behavior in social trap situations. Journal of Experimental Social Psychology, 19, 522-539.

Schulz, N., Parisi, F., \& Depoorter, B. (2002). Fragmentation of property: Towards a general model. Journal of Institutional and Theoretical Economics, 159, 594-613.

Schwartz, S. H. (1970). Elicitation of moral obligation and self-sacrificing behavior. Journal of Personality and Social Psychology, 15, 283-293.

Schwartz, S. H. (1977). Normative influences on altruism. In L. Berkowitz (Ed.), Advances in Experimental Social Psychology: Vol. 10 (pp. 221-279). New York: Academic Press.

Schwartz, S. H., \& Howard, J. A. (1982). Helping and cooperation: A self-based motivational model. In V. J. Derlega \& J. Grzelak (Eds.), Cooperation and helping: Theories and research. New York: Academic Press.

Schwartz-Shea, P., \& Simmons, R. T. (1995). Social dilemmas and perceptions: experiments on framing and inconsequentiality. In D. Schroeder (Ed.), Social dilemmas: Perspectives on individuals and groups (pp. 87-103). Westport, CT: Praeger.

Smith, R. J. (1981). Resolving the tragedy of the commons by creating private property-rights in wildlife. Cato Journal, 1, 438-468.

Stern, P. C. (1976). Effects of incentives and education in resource conservation decisions in a simulated commons dilemma. Journal of Personality and Social Psychology, 34, 1285-1292.

Stevens, M., Lammertyn, J., Verbruggen, F., \&Vandierendonck, A. (2006). Tscope: A C library for programming cognitive experiments on the MS Windows platform, Behavior Research Methods, 38, 280-286. 
Thaler, R. H. (1980). Toward a positive theory of consumer choice. Journal of Economic Behavior and Organization, 1, 39-60.

Thompson, S. C., \& Stoutemeyer, K. (1991). Water use as a commons dilemma. The effects of education that focuses on long-term consequences and individual action. Environment and Behavior, 23, 314-333.

van Dijk, E. \& van Knippenberg, D. (1996). Buying and selling exchange goods: Loss aversion and the endowment effect. Journal of Economic Psychology 17, 517-524. van Dijk, E., \& Wilke, H. (1997). Is it mine or is it ours? Framing property rights and decision making in social dilemmas. Organizational Behavior and Human Decision Processes, 71, 195-209.

van Dijk, E., \& Wilke, H. (2000). Decision-induced focusing in social dilemmas: Give-some, keep-some, take-some, and leave-some dilemmas. Journal of Personality and Social Psychology, 78, 92-104.

van Dijk, E., Wit, A., Wilke, H., \& Budescu, D. V. (2004). What we know (and do not know) about the effects of uncertainty on behavior in social dilemmas. In R. Suleiman, D. V. Budescu, I. Fischer, \& D. M. Messick (Eds.), Contemporary Psychological Research on Social Dilemmas (pp. 315-331). Cambridge: Cambridge University Press.

Van Hiel, A., Vanneste, S., \& De Cremer, D. (2008). Why did they ask so much? The role of causal attributions in explaining cooperation in commons and anticommons dilemmas. Journal of Applied Social Psychology, 38, 173-197.

Vanneste, S., Van Hiel, A., Parisi, F., \& Depoorter, B. (2006). From tragedy to disaster: Welfare effects of commons and anticommons dilemmas. International Review of Law and Economy, 26, 104-122. 
Weber, J. M., Kopelman, S., \& Messick, S. M. (2004). A conceptual review of decision making in social dilemmas: Applying a logic of appropriateness. Personality and Social Psychology Review, 8, 281-307. 


\section{AUTHOR'S BIOGRAPHIES}

Kristof Dhont is a scientific researcher at the Department of Developmental, Personality and Social Psychology at Ghent University, Belgium. His current research interests include inter- and intragroup processes, prejudice, social attitudes and political psychology.

Alain Van Hiel is Associate Professor at the Department of Developmental, Personality and Social Psychology at Ghent University, Belgium. He teaches courses on social psychology to students in Psychology, Criminology, Law, Political Science and Sociology and his current research interests include group processes, political psychology and social cognition.

David De Cremer is Professor of Behavioral Business Ethics at Rotterdam School of Management, Erasmus University, Scientific director of the Erasmus Centre of Behavioral Ethics (www.erim.nl/behaviouralethics), and visiting professor at London Business School and Ghent University. His current research interests are ethical leadership and organizational justice, behavioural business ethics, bargaining and social dilemmas, trust and trust repair. 
Table 1. Pay-off scheme used in Study 1

\begin{tabular}{|c|c|c|c|c|}
\hline Choice & $\begin{array}{l}\text { Amount of } \\
\text { money you } \\
\text { take }^{\mathrm{a}}\end{array}$ & $\begin{array}{c}\text { (1) } \\
\text { Probability on } \\
\text { value } \\
\text { preservation of } \\
\text { the oil source }\end{array}$ & $\begin{array}{c}(2) \\
\text { Probability that } \\
\text { other companies } \\
\text { can benefit }\end{array}$ & $\begin{array}{c}\text { Probability on } \\
\text { value } \\
\text { preservation } \\
\text { AND that other } \\
\text { companies can } \\
\text { benefit }\end{array}$ \\
\hline$\diamond$ & 0 & $100 \%$ & $100 \%$ & Here you have to \\
\hline$\diamond$ & 5000 & $100 \%$ & $100 \%$ & take (1) AND (2) \\
\hline$\diamond$ & 10000 & $100 \%$ & $100 \%$ & into account. \\
\hline$\diamond$ & 15000 & $90 \%$ & $90 \%$ & In other words \\
\hline$\diamond$ & 20000 & $80 \%$ & $80 \%$ & you have to \\
\hline$\diamond$ & 25000 & $70 \%$ & $70 \%$ & combine both \\
\hline$\diamond$ & 30000 & $60 \%$ & $60 \%$ & columns. \\
\hline$\diamond$ & 35000 & $50 \%$ & $50 \%$ & \\
\hline$\diamond$ & 40000 & $40 \%$ & $40 \%$ & \\
\hline$\diamond$ & 45000 & $30 \%$ & $30 \%$ & \\
\hline$\diamond$ & 50000 & $20 \%$ & $20 \%$ & \\
\hline$\diamond$ & 55000 & $10 \%$ & $10 \%$ & \\
\hline$\diamond$ & 60000 & $0 \%$ & $0 \%$ & \\
\hline
\end{tabular}

${ }^{\mathrm{a}}$ In the anticommons condition this label was changed into "Money you ask from B as compensation". 


\section{Figure Caption}

Figure 1. Use and exclusion in commons and anticommons dilemmas, adapted from Vanneste et al. (2006)

Figure 2. Mean amounts of money (with $S D$ 's between brackets) as a function of externalities salience and dilemma type in Study 1

Figure 3. Mean amounts of money (Figure 3a) and awareness of the externalities (Figure $3 b$ ) (with $S D$ 's between brackets) as a function of externalities salience and dilemma type in Study 2 
Figure 1

Anticommons

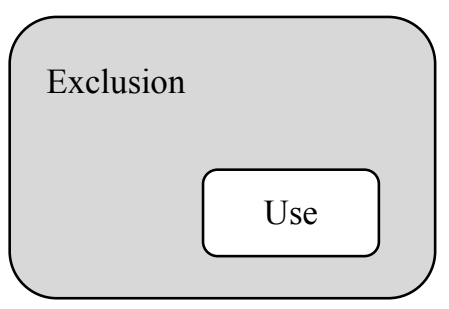

'Normal'

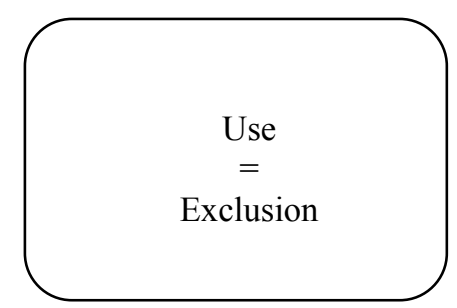

Commons

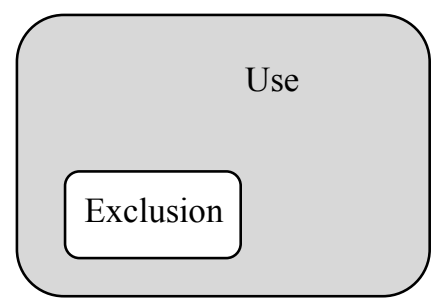


Externalities awareness in anticommons dilemmas 40

Figure 2

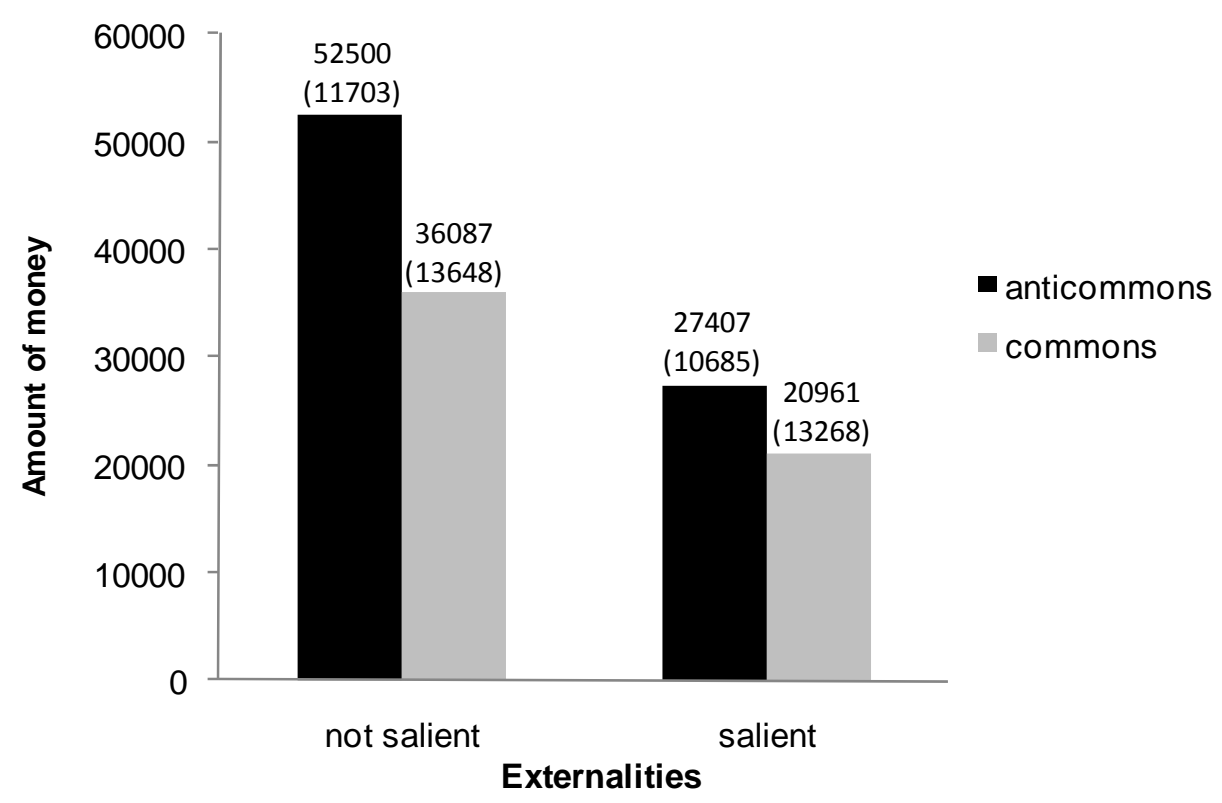


Figure 3

a

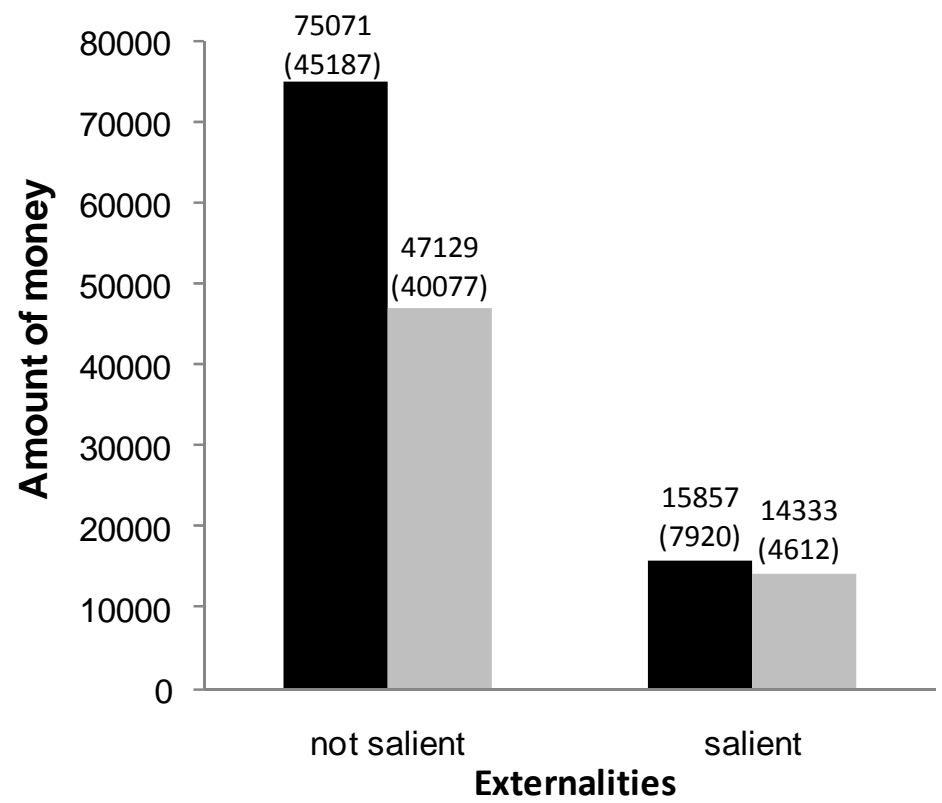

anticommons

commons

b

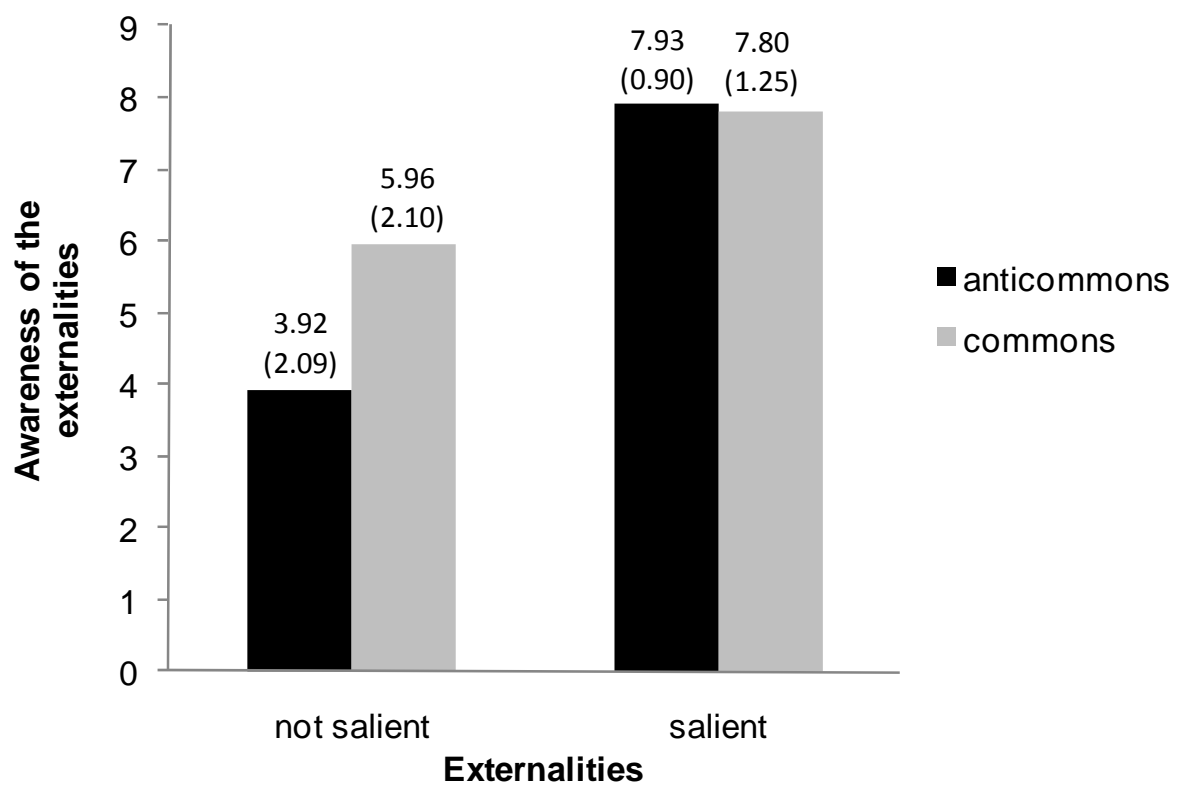

